\title{
The Impact of Future Social and Technological Trends On the Dissemination of Census Bureau Information
}

\author{
by Donald L. Day' \\ School of Information Studies \\ Syracuse University
}

\begin{abstract}
This study examines social and technological trends that may impact the dissemination of U.S. census information via the Depository Library Program in the Year 2000 and beyond.
\end{abstract}

The study looks beyond currently emerging systems to examine a limited list of future issues in technology, regulation, funding, access, and user demand. It examines information dissemination in the broad, societal context, rather than concentrating narrowly upon the means of delivery. Its main objectives are to pinpoint key issues, to stimulate an appreciation of the inextricable nature of information in postindustrial society, and to recommend policies and directions for further research.

\section{Introduction}

\section{Nature of the Topic}

This study examines social and technological trends that may impact the dissemination of U.S. census information via the Depository Library Program in the Year 2000 and beyond.

\section{Importance of the Topic}

Establishing the social and technological context within which census information might be disseminated in the future would facilitate rational policy making regarding that dissemination. It also might save time and money, in that decisions about systems with long lead times could be made so as to implement the systems in a timely and efficient manner.

\section{Scope and Objectives}

The original impetus for the study was a concern about the sheer volume of paper products absorbed by the Depository Library Program (as high as 25 percent of all documents printed from the 1980 census), and an interest in how new technologies may make it possible to reduce costs while increasing the availability and variety of data (in particular, census data).

The study looks beyond currently emerging systems to examine a limited list of future issues in technology, regulation, funding, access, and user demand. It examines information dissemination in the broad, societal context, rather than concentrating narrowly upon the means of delivery. Its main objectives are to pinpoint key issues, to stimulate an appreciation of the inextricable nature of information in postindustrial society, and to recommend policies and directions for further research.

\section{Point of View}

This study was fielded under the presumption that government will be required to continue providing public access to federal information as part of its commitment to maintaining the informed citizenry that is central to participatory democracy.

\section{Report Oulline}

Following a brief review of study methodology, this report presents an overview of future trends (the societal context), a discussion of study findings, and policy recommendations for key issues requiring public debate.

\section{Study Method \\ Design}

The current study was conceived as a qualitative, exploratory and descriptive effort to identify issues of concern. Elite interviewing was to be interspersed with a review of literature in the future studies field in an iterative process that would develop perspective and deepen focus and selectivity in data collection.

The interviews were in-depth but informal, as recommended by Marshall \& Rossman (1989). They were conducted in subjects' normal work environment (a "natural setting") to ensure ease of discussion and immediate access to reference materials.

\section{Procedure}

Subjects were selected because of their expert knowledge of federal information dissemination policies and of developing technology. Interviews were conducted in two rounds, separated by approximately four weeks. The first set concentrated on preliminary data gathering and focused upon the Depository Library Program. The second set was guided by an outline of concerns (interrogative research questions) developed from the literature and from the earlier interviews (see below). Sessions were recorded to ensure the completeness of notes and to help recognize nuances that might have been overlooked at the time of initial data collection. Only one subject 
was distracted by the presence of a taping machine; the others were largely oblivious to its presence.

The scheduling of multiple interview events separated by a review of the literature and by conceptual outlining worked very well in focusing the research and in identifying issues that were not apparent at the outset. An improvement in procedurc that might be useful in other qualitative research on this or other topics would be submission of interim reports to key sources for critique.

This technique might help sources to feel involved in the research effort, tend to focus their comments during interviews, and encourage them to act as agents of the researcher in obtaining material useful to the study.

\section{Key Research Questions}

The key research questions drafted from an analysis of the literature and during the interviewing process were as follows.

I. What will be the leading edge information technologies in the first decade of the next century?

2. When and to what degree will depository library materials (especially census data) be distributed via CD-ROM or other machinereadable media?

3. What technological developments will affect patrons' remote electronic access to depository libraries?

4. What software and data structures will be required for electronically disseminated census data, to facilitate rapid and effective searches and retrieval?

5. What will be the sponsorship and impact of standardization efforts to facilitate network access to federal government information?

6. To what extent will anti-trust concerns inhibit development of data integration protocols and telecommunications software necessary for widespread network access to federal government information?

7. How will the distribution of government information be controlled, under whose auspices and with what objectives?

8. How will data integrity be maintained without impeding widespread electronic dissemination of information?
9. Which sponsors of information production, dissemination and use will support high technology access, under what conditions and with what goals?

10. What are the prospects that Congress will choose to privatize depository library distribution? What impact would that have upon the quality, quantity, availability and cost of Census Bureau information?

11. What will be the minimum skill levels required of users and depository librarians in accessing electronically disseminated information?

12. To what degree might user fees and other costs of accessing electronically disseminated information disenfranchise individuals?

13. What impact will changes in work force composition and employment arrangements have upon the types of census information sought by users?

\section{Overview of Future Trends}

The Economy

Although estimates vary widely, some projections forecast a period of modest economic prosperity for the United States in the next two decades, including a strong rise in "knowledge industries."

Demographers predict an enlargement of the middle class, with fewer very poor or very wealthy. Cultural homogenization is anticipated, despite an increase in non-English speakers and the swelling ranks of citizens over 65 , with each group having its own unique perspective and needs (Cetron, 1988).

Information consumption may be influenced significantly by an increase in middle class affluence. The incomes of middle-aged citizens will rise about three-fourths. Onethird of middle-aged households will have annual incomes of $\$ 50,000$ or more, in constant dollars (New American, 1986). More sophisticated, better-educated consumers with work experience will have disposable income for travel, leisure and luxury. Spending will continue to shift toward service industries (Cetron, 1988).

\section{Education and Training}

Four percent of the labor force may be in job retraining programs in the coming decade (Cetron, 1988). There may be more rigorous educational standards at all levels and a greater concern for human rights and personal freedom (Caddy, 1987).

Work Force Composition 
By the Year 2000, manufacturing will employ only nine percent of the labor force, with services taking 88 percent, partly because productivity in automated industries may increase fivefold. Seventy percent of U.S. homes may have computers in 2000 , facilitating the potential for widespread remote access to federal government information (Cetron, 1988).

Changes in the work force may be a key influence during the next decade. The mandatory retirement age may be 70 by the Year 2000 . Union members will comprise less than 10 percent of the labor force (versus 29 percent in 1975 and 18 percent in 1985). The work force will be dynamic, with people changing careers an average of every 10 years. A shortage of low-wage workers will force businesses to automate and to seek foreign workers. The ranks of the self-employed will grow at a faster rate than salaried workers and more mid-career professionals will become entrepreneurs (Cetron, 1988).

Some expect a crisis of consumer confidence in the U.S. technological infrastructure as widespread hacker activity plagues computer networks (1988 Ten-Year Forecast, 1988).

Also anticipated are a decrease in the divorce rate, an increase in marriages and family formation, and a heightened role for religion. Do-it-yourself activities will be popular, because a 32-hour work week will create more leisure time and due to the high cost of services. Protracted adolescence may be more common, although there will be far fewer young people than at present. A decrease in the size of federal government will be accompanied by growth in state and local governments (Cetron, 1988).

\section{Knowledge Industries}

The United States is becoming a postindustrial society. In such a system, telecommunications and computers are vital to the exchange of information and knowledge (Bell, 1978). Multimedia information networks permeate everyday life. New information and processing devices increase productivity, despite initial retraining losses. Knowledge industries grow in importance.

As the central role of information accelerates, major policy issues will include privacy, the part government plays in information dissemination, intellectual property rights and functional literacy. Neural networks (combinations of electronic and photonic circuits used in optical computers) may be one of the key new technologies. The science of integrating diverse telecommunications and computing systems may become an important driver of technological innovation (Bezold and Olson, 1986).

Information Technologies
Despite the increasing use of computers in a wide variety of applications, there also may be an increase in the need for paper. Tenner (1988) reported that from 1959 to 1986 U.S. consumption of writing and printing paper increased 320 percent while real GNP rose only 280 percent. He believed that electronic information supplemented rather than replaced paper, and noted that using paper is more efficient, legible, and secure than working with monitor displays. Tenner also predicted that increases in the number of office workers will cause a corresponding growth in the use of photocopiers and facsimile machines (which use paper).

Massive increases in storage technology will take place, with commercial system capacities in the hundreds of megabytes. Optical disks (some erasable) will emerge as the medium of choice in applications such as census data retrieval that require high storage capacity, fast access, removability, non-contact recording, and long life. Engineers predict that current disk capacity will increase tenfold and that the 600 megabyte disk that now sells for $\$ 200$ is likely to cost only $\$ 25-50$ (Freese, 1988).

\section{Knowledge in Postindustrial Society \\ The Economics of Information}

Social organization will be shaped by intellectual technology in postindustrial America. Since information and knowledge are not depleted in the sense that goods are in an industrial economy, knowledge will be considered a social product. Its cost, price and value will be assessed in a way vastly different from that for industrial goods, in accordance with what is known as the "Knowledge Theory of Value" (Bell, 1978).

Knowledge, even when it is sold, remains with the producer. It is a "collective good" - once it has been created, it is available to all. There is little incentive for any single person or enterprise to pay for the production of knowledge unless a proprietary advantage (such as a patent or copyright registration) can be obtained. Thus, government policy in regard to intellectual property and contractor marketing of publicly funded products will be key in the management of future information dissemination technology.

Bell (1978) believes that a reduction in incentives for individuals or companies to produce knowledge will cause the responsibility for and costs of satisfying information needs to fall to government. Whether information dissemination is "privatized" and in what manner may affect the availability of that information significantly.

The first infrastructure placed in service by industrializing economies is transportaion. Fully industrial systems concentrate on energy utilities. Societies entering the 
postindustrial phase need advanced telecommunications. Therefore, the major technological problem for America in the next decade will be emplacement of an appropriate digital information network, carried over fiber optic cable (Bell, 1978).

\section{Social Impacts}

The U.S. as postindustrial state is likely to have a vastly different social structure than at present. Bell (1978) believes that this new order may be characterized by:

1. Centrality of theoretical knowledge as the basis of innovation.

2. Creation of new intellectual techniques to engineer solutions to economic (and even social) problems.

3. The spread of a (technical and professional) knowledge class.

4. The change from goods to human services.

5. A change in the character of work (people must learn to live with one another, since interaction among groups will be key).

6. The employment of women in expanded human services.

7. Science as the societal standard bearer.

8. Political units comprised of either vertical organizations of individuals into scientific, technological, administrative, and cultural centers, or of institutions arrayed as economic, government, university, or social complexes.

9. Meritocracy (an emphasis on education and skill).

10. Scarcities of information and of time.

11. The economics of information.

Bell (1978) also believes that information by its nature is collective, not private. In postindustrial America, the optimal social investment in knowledge may require that we follow a cooperative strategy to increase, spread and use knowledge.

A more pessimistic view of the impact of advanced telecommunications technology is taken by Eldredge (1978). Hebelieves that new technology will:

1. Will be highly beneficial to some segments of society, but detrimental to others.

2. Will have a positive impact primarily in the middle-class suburbs, with a negative impact in central cities.

3. Will not be properly understood and regulated until considerable damage has been done in major urban development.

4. Will reduce the economic viability of the central city by accelerating delocalization of business and commerce.

5. Will affect the service sector most, because its processes involve paper transactions that are particularly sensitive to technological substitution.

\section{The Depository Library Program}

It is within this context of an increasingly central role for the development and dissemination of information that we consider future management of the Depository Library Program.

The federal government has a long history of providing increasing amounts of information to the public as part of its responsibility to maintain an informed citizenry.

In particular, substantial volumes of information ranging from census data to contract studies of government activities to congressional hearings have been disseminated in a network of some 1400 libraries as part of the Depository Library Program. Under the program, government-printed material is distributed to a limited number of regional depository libraries. Additional "select" libraries also archive some subset of these materials for their patrons. ${ }^{2}$

Recently, census data have been distributed to a few depository libraries on CD-ROM in an effort to assess the medium's potential, as well as to gauge user reaction. ${ }^{3}$ Bureau of the Census material also is available to institutions and to the public at State Data Centers operated specifically for that purpose.

\section{Discussion of Key Research Questions in Terms of Findings}

Elite interviewing and the literature review for this study identified five major areas that may affect future dissemination of census data as part of the Depository Library Program. These areas were selected based upon the emphasis they were given by interviewees and upon the author's experience in information systems design.

\section{Technology}



2. Regulation
3. Funding
4. Access
5. User Demand

\section{Technology \\ Leading Edge Technologies}

What will be the leading edge information technologies in the first decade of the next century?

The media used in dissemination of federal information in the Year 2000 may be a mixture of optimized currentday technologies (McGee, 1990).

Data input, the bane of current full-text efforts, may no longer be a problem. Research during the past few years has made it possible for many agencies (e.g., the Air Force) to use improved optical scanning devices to make large amounts of printed text machine-readable (McGee, 1990). Once standards are established for sharing scanned input, an enormous amount of digital data will be available, although coordination and retrieval problems will need to be addressed.

Information dissemination also may include specially engraved static memory chips for advanced personal computers. Response time typical of such devices would be significantly shorter than with mechanical access systems - an important consideration for complex, natural language queries of large databases. Inexpensive, high-capacity chips will be available. (In a recent demonstration, IBM technicians wrote patterns at singleatom resolution using a scanning tunnelling microscope. ${ }^{4}$

Thus far, vast sums of money have been spent on advanced technologies without any real understanding of how people might interrelate with these devices (Weiner \& Brown, 1989). Current improvements center on the ability to gather, store, and catalog information.

Much information dissemination in the Year 2000 will be via fiber optic cable, which due to its enormous capacity will compete effectively with relatively limited capacity direct-broadcast satellite transmission in many real time access applications. Much of the internal transmission capacity of most telephone companies already has been converted to fiber, and a number of large businesses have access to fiber networks. All subscribers are certain to be fiber-connected in 25 years, with many equipped during the 1990s (Weinstein \& Shumate, 1989).
There will be an explosion of communications options as the fiber optic infrastructure is installed, making possible single transmission, multiple-service options such as online catalog ordering and public opinion polling (due to the signal capacity of fiber optic cable). Today, the Integrated Services Digital Network (ISDN) makes possible voice, data and image transmission over the same phone lines. ISDN is likely to be deployed widely by the end of century, making possible high fidelity audio and five-second per page facsimile. Early in the next century, ISDN will give way to the Broadband Integrated Services Digital Network (BISDN) - an intelligent networks supporting high quality, simultaneous and on-demand video services, home telemetry, and high speed data and image communication among faxes, workstations and computers. The Telecommunications Network for the Deaf (TND) will convert speech into text and vice versa to assist handicapped subscribers. These and other protocols may be tested soon in the NREN high-speed network already in use at many libraries.

CD-ROM and on-line technology early in the next century will assist the user in sorting through the thicket of available information by means of "information grazing": an intelligent, user-selectable filtering system capable of passing only items of interest in order to manage information overload.

\section{Machine-Readable Media}

When and to what degree will depository library materials (especially census data) be distributed via CD-ROM or other machine-readable media?

It is already within the means of depository libraries to provide public access to census data via CD-ROM. Recently, the Bureau of the Census has been engaged in a test distribution of files on CD-ROM to depository libraries throughout the country (J. Stratford, personal communication, February 21, 1990).

However, the test discs have not been received well by all depositories. Data on one disc were formatted in a different pattern for each file, making it necessary for users to apply different techniques to access each dataset. These variations in format have decreased the usefulness of the disc (K. Chiang, personal communication, April 12, 1990). Also, a virus was distributed on the 1988 County and City Data Book CD-ROM, though prompt action by the Depository Library Program appears to have averted serious problems for member libraries (Harm, 1990).

Despite such initial problems, CD-ROM seems ideally suited to dissemination of census information which by 
its nature contains large amounts of data. In the mid1980 s, Grolier placed its 21-volume, nine-million word Academic American Encyclopedia on a single compact disc. Eighty percent of the disc's capacity remained unused. In addition to enormous space savings, use of CD-ROM made possible high-speed keyword searches (Cornish, 1985).

In the future, CDs will not necessarily be distributed to all institutions in the Depository Library Program. Much in the way that only regional libraries receive full dissemination now, some expect discs bearing federal information to be distributed only to regional depository libraries. Select libraries could request discs on loan as required by their patrons. (McGee, 1990).

\section{Remote Electronic Access}

What technological developments will affect patrons' remote electronic access to depository libraries?

CD-ROM will by no means be the only electronic access to federal information in the years ahead. Combinations of new and existing technologies will facilitate the widespread availability of census data early in the $21 \mathrm{st}$ Century.

Integration of facsimile devices with home entertainment centers will allow users to receive hardcopy on demand of a wide range of federal govemment information, if online access to depository databases is allowed. Installation of fiber-optic cable to homes and businesses will make possible a dynamic, interactive census process in which users not only access more current database information but also can register data about themselves more easily and more frequently than is possible with current, paper-based census techniques. The Year 2000 may be the last "traditional" census, as citizens enter the data collection, processing, analysis and dissemination loop more actively.

Such dynamic census systems would raise issues of quality control, user cooperation, and prevention of abuse by commercial marketing interests. Extension of on-line access to the full range of depository data also may call into question the need for regionally distributed depository archives.

Most depository libraries already are involved in networks. There are 20 regional networks, plus some CDROM distribution. Some federal information specialists feel that depository library information should be on-line, if only to reduce the expense of storing information that is used infrequently. Now, it is enormously expensive and wasteful to print and distribute materials that few if any patrons use: "Much of government information is a record going nowhere." (McGee, 1990).

Regardless of storage capacity, it still will be necessary to keep truly unused information from clogging the system. It has been suggested that librarians help define the characteristics of a filter to be used in deciding what depository information should be part of on-line and CDROM databases. Information use could be evaluated at regional libraries, or such institutions could delegate responsibility to subject specialists. However, many librarians resist the filtering of information, preferring to make decisions on a case-by-case basis rather than allow data to be withheld at centralized distribution points (McGee, 1990).

\section{Software and Data Structures}

What software and data structures will be required for electronically disseminated census data, to facilitate rapid and effective searches and retrieval?

The complexity and volume of federal information in all formats will require sophisticated indexing and retrieval software, but existing government databases are seriously lacking in such tools (McGee, 1990). Software used currently to access the test CD-ROMs distributed by the Bureau of the Census also may be inadequate ("Until there is adequate access software, the CD is not much of an improvement on a stack of microfiche." $-\mathrm{K}$. Chiang, personal communication, April 12, 1990).

Efficient software will need to be developed to manage the volume of machine-readable information available in the future. When the mass of retrievable information is more than the brain can process effectively, the result is not faster decision making, but instead a delay in or even abdication of decision making (Weiner \& Brown, 1989). Clarke (1985) noted that without adequate indexing, many users would be completely overwhelmed by a virtually limitless selection of information resources, and chose to select nothing. He also pointed out that

With the latest techniques, it would be possible to put the whole of human knowledge into a shoe box. The problem, of course, is to get it out again; anything misfiled would be irretrievably lost.

Within the next decade, artificial intelligence will be applied to such problems (Diebold, 1985).

Some data in future federal databases may need to be in a format suitable for manipulation by spreadsheet and statistical programs such as Lotus 1-2-3 or SAS (McGee, 1990). The widespread availability of relatively inexpensive bitmapped displays, faster processors, and a demand for three-dimensional graphics and photographic-quality images may force some network databases to be stored in 
tokenized or vector formats to be regenerated at user workstations. (Graphics regeneration has been available for some time on more expensive minicomputers such as the DEC MicroVax II, using the ANSI/ISO-standard Graphical Kernel System.) Such formats allow specialized processors in users' machines to plot images from line endpoint data rather simply displaying full-screen files downloaded from host computers. This capability would accelerate display speeds significantly, partly due to new data compression techniques and the capacity of fully digital, high speed networks to download enormous amounts of data.

\section{Regulation}

The history of innovation is replete with examples of new technology that was not implemented to its potential because of social or political factors that frustrated its use. Future data dissemination technology could suffer a similar fate if issues of standardization, anti-trust, control of distribution and data integrity are not addressed adequately.

\section{Standardization}

What will be the sponsorship and impact of standardization efforts to facilitate network access to federal government information?

The architecture of future data access systems and the standards coordination required for integration of diverse computing hardware are key concems that will nced to be addressed as technology makes large volumes of federal data available in machine-readable format. As Clarke (1985) observed,

\section{Another problem is to decide whether we mass produce the shoe boxes [databases], so that every family has one, or whether we have a central shoe box linked to the home with wideband communications.}

Information specialists at the Library of Congress believe that a single, coordinated, national database with remote access is not likely. Interface standards will make possible an extensive, distributed architecture populated with vastly different hardware in a highly interconnected system. (Substantial interconnection already exists among NTIS, DOE and Medline.) They feel that the centralized database concept is obsolete. In this view, future on- line access to federal information would more likely be via highly distributed sclective centers, linked to each other using standard protocols (Bortnick \& Relyea, I990).

Establishment of standards for such on-line networks is a key concern, since integration of computers from a multitude of vendors operating under vastly different operating systems may be involved. Equipment already in place at user sites could be linked to provide reasonably economical service, if sufficient standards were developed by government and applied as part of the access system. Standards may not even be imposed by the federal government, but instead by international entities, owing to the substantial interconnection even now between federal government data stores and overseas sources. European networks have tended to be further advanced than those in the U.S., therefore are more likely to drive any movement toward standardization (Bortnick \& Relyea, 1990).

If an institution could not link to the system using existing hardware because its plant was antiquated, funding could be requested from corporations, the Department of Commerce and/or the National Science Foundation to bring the site to minimum levels for participation in the system. Otherwise, it would be presumed that institutions could tap into the on-line system with existing equipment and software, if they met standards (Bortnick \& Relyea, 1990).

At present, standardization even within the federal government is difficult. Many agencies have material in electronic form, but there is no coordination of data formats or machine compatibility. Most electronically stored data are not available outside their host agency. Although the Office of Management and Budget (OMB) or General Services Administration (GSA) may have the authority to force coordination of data formats throughout the federal government, it remains to be seen whether that authority will be applied, and with what result (Powell, 1990).

\section{Anti-Trust Concerns}

To what extent will anti-trust concerns inhibit development of data integration protocols and telccommunications software necessary for widespread network access to federal government information?

Traditionally, federal anti-trust law has prevented firms in competition with each other from cooperating in ways that may be necessary for development of standardized protocols, equipment and software for the fully integrated information systems of the future. However, anti-trust law has changed in recent years to allow cooperative research and development among firms, largely in response to competitive market pressures from overseas (where such cooperation is common) (Bortnick \& Relyea, 1990).

There are proposals in Congress to extend this liberalization to include product development and even production. The availability of seamless networks for user access to on-line federal information would be affected 
significantly by greater cooperation among service suppliers, if they were not constrained by anti-trust regulation.

Federal anti-trust enforcement has been dormant in recent years, in part because there have been few substantive changes in business activity from old, established patterns. However, the new information technology constitutes just such a substantive change, implying the need for changes that would facilitate cooperative development of technologies - especially protocols and access software - that would facilitate interconnection (Bortnick \& Relyea, 1990)

\section{Control of Distribution}

How will the distribution of government information be controlled, under whose auspices and with what objectuves?

Telecommunications policy centers around who provides services, under what conditions, and at what prices.

A jurisdictional struggle is under way now among the Government Printing Office (GPO), OMB, National Technical Information Service (NTIS) and others over control of federal information dissemination. The GPO is funded by the legislative branch; clashes take place between the executive branch and Congress over information policy. Each side has its allies in Congress. (Both the House and Senate have committees with oversight authority for each agency involved in the policy debate.) Paperwork reduction is the concern of the Senate Committee on Government Affairs ${ }^{5}$, statistical policy is set by the Bureau of the Census, and the Depository Library Program is managed by the Joint Committee on Printing. Commerce and Science committees also are involved, because of technology issues. It is difficult to make policy with such fragmentation (Powell, 1990), and just as difficult to implement it because of the tug of war among the actors in their attempts to influence appropriations.

House bill 3849 (introduced in January) is one manisfestation of the struggle. This legislation attempts to prevent public monies from being used by the executive branch to generate and distribute information products and services without involvement of GPO. It broadens the legal definition of "documents" to include information products "in any tangible format, medium or substate", and attempts to interpose the Superintendent of Documents between the depository libraries and any government agency that might issue information products (Government, 1990).

This oversight problem must be resolved before the depository system can upgrade, regardless of the benefits of technology. Some observers feel that the Depository Library Program will need to be removed from GPO auspices before its technological potential can be fully realized, in part because the GPO work force is hesitant to diversify from traditional media (Bortnick \& Relyea, 1990).

Some parts of the library community feel threatened by the new attempts to centralize and standardize the new technology. In 1985, OMB's Office of Information and Regulatory Affairs issued Bulletin A-130, which dealt with dissemination of federal information in electronic format and was part of the effort to reduce the volume of government printing (Powell, 1990). Some librarians felt the policy would undercut the depository library system (Powell, 1990). Initially, the cost of advanced technology may buturess such resistance by those who favor hardcopy dissemination (McGee, 1990).

Questions of access to federal information networks also need to be addressed before practical implementation of rapidly developing technology. Some within the federal community feel that capabilities such as full-text retrieval should be available to all citizens, not merely to depository libraries (McGee, 1990).

Some concern has been expressed within government regarding regulation specifically of the on-line dissemination of federal information due to provisions of the Export Administration Act (PL96-72). They feel that the competitiveness of American industry might be impaired if information were available to foreign competition. Also, DoD is concerned about the "mosaic theory" potential of widespread, machine-readable federal information (i.e., what new knowledge can be gained from machine correlation of public information).

Therefore, policy will need to be made regarding whether on- line information should be available only to U.S. citizens. Restriction may not be feasible regardless of policy because of the difficulties of controlling information transfer in an environment of total interchangeability among data formats. Release in one format would be tantamount to release in all others (Bortnick \& Relyea, 1990).

Further frustrating attempts to limit overseas access to federal information is the fact that a great deal of information in existing federal databases (e.g., NTIS or DOE) is from foreign sources. It is unlikely that overseas concerns would be willing to continue providing substantial amounts of information to a U.S. database if they were not allowed in tum to access that database.

In any case, controls cost money which might not be forthcoming, depending upon the perceived importance 
of such restrictions compared to the perceived need for convenient and widespread public access to federal government information.

\section{Data Integrity}

How will data integrity be maintained without impeding widespread electronic dissemination of information?

Data in a freely accessed, on-line system could be copied, modified then redistributed, without the knowledge of the issuing agency. Original data may even be subject to accidental or malicious corruption. It might be difficult to protect important data whose accuracy would be presumed to be the responsibility of the Bureau of the Census (Bortnick \& Relyea, 1990).

With the advent of new technology, however, a different model of responsibility might be in place. In the past, a publisher may have been expected in certain circumstances to notify the trade media (e.g., Publishers Weekly) about serious errors discovered after a book was distributed. Easily modified works such as those marketed in three-ring notebooks or with spiral bindings could have been distorted in the field, totally unknown to the original publisher. In the analogous future situation with machine-readable material, the aspect of the technology that makes data easy to corrupt also makes unauthorized changes relatively easy to correct, if intrusions can be detected.

\section{Funding}

\section{Sponsors}

Which sponsors of information production, dissemination and use will support high technology access, under what conditions and with what goals?

Funding is a natural barrier to the widespread dissemination of information. Who should be responsible for capital equipment and telecommunications costs incurred if patrons or depository librarians are to have on-line access to census data?

In all probability, future funding for information dissemination would follow existing models. These include (I) a prototype database access system sponsored by the Library of Congress, (2) the regional supercomputer program, and (3) the Federal Information Center Program.

In the Library of Congress model, 12 librarics, corporations and agencies across the U.S. use their own equipment and staff, and pay their own telecommunications charges. The Library maintains the database and pro- vides access to its computers (Bortnick \& Relyea, 1990). The Internet communications network operates on a similar model. Universities across the world provide their own equipment and software; the U.S. government maintains the relatively small interconnection "backbone" of the system.

In the regional supercomputer program model, access to information is restricted to institutions that provide financial and support for the system. Contracts between government and the universities hosting the centers include specific provisions for use and funding. Centers typically solicit financial support from two or three distinct sources (Bortnick \& Relyea, 1990). Under this model, depository libraries might maintain regional CDROM or on- line database centers which loan discs or provide logon accounts to institutions that pay to support the system. Whether the subscribing institutions in turn charge their patrons for access is a major policy option.

Some at the Library of Congress feel that the Depository Library program should be subsumed by the GSA's Federal lnformation Center (FIC) Program, making it the central point from which to access many types of integrated media. These Centers are not funded solely by the legislative branch, but instead are supported by many sources under a "plurality of funding" concept that is more acceptable politically (Bortnick \& Relyea, 1990). Under the FIC model, a private firm (Biospherics, Incorporated of Beltsville, Maryland) manages regional offices which field telephoned inquiries regarding a wide range of government scrvices, programs and regulations. By terms of the contract, Biospherics is is required to provide access to the hearing and speech impaired (Federal, 1990). Under this model, depository library materials presumably would be accessed on-line using regional FIC database systems.

Depository libraries are not very high on the political agenda in Congress, since their funding comes directly from the legislative branch budget. Many legislators believe that government should provide the information, but not the means for its distribution. In the future, the federal subsidy for information dissemination might be limited to the current cost of paper distribution (Bortnick \& Relyea, 1990).

Telecommunication charges for the dissemination of federal information may be regulated in the future by policies such as the FCC Open Network Architecture (ONA) initiative. ONA's intent is to prevent monopoly control by local telephone carriers of connections to national networks. The initiative requires modular pricing of discriminible services, to promote competition among suppliers. 
If on-line access to depository library information is to be provided in the home, then charges for terminal electronics and for the in-ground installation of fiber-optic cable must be comparable to the total cost of a typical telephone line installation today: $\$ 1,000$ to $\$ 1,500$ per home. Network operation also must be economically feasible. That it may be is demonstrated by research at Bellcore which has resulted in experimental models of broadband, digital networks (Weinstein \& Shumate, 1989).

During the more than a century that the depository library program has provided public information to participating institutions, the government has funded the printing and dissemination of materials. Changes in perception of government's proper role - and in its ability to support initially expensive dissemination technology - make it doubtful that future funding will come from Washington alone.

Funding expanded network access in particular is a serious concern. Some federal information specialists believe that future on-line systems will need to be feebased. Federal libraries already pay for on-line access, in a manner similar to that used to charge commercial customers for access to commercial databases such as Dialog.

Despite these concerns, some analysts believe that basic information utilities of the future will be economical to the point of being taken for granted. Their concern is that such a cheapening of information will risk potential devaluation of product quality and intellectual creativity (Diebold, 1985). It should be noted, however, that low cost does not necessarily translate into easy access. Regardless of cost, there still will be a need to filter the vast amounts of information that will be available in order to retrieve only what is needed.

\section{Privatization}

What are the prospects that Congress will choose to privatize depository library distribution? What impact would that have upon the quality, quantity, availability and cost of Census Bureau information?

There are some who feel that OMB's Circular A-130 (and the corresponding requirement for A-76 studies) ${ }^{6}$ is too favorable to the private sector, because it urges agencies to contract for information services (Powell, 1990). This sentiment underlies HR 3849, the Government Printing Office Improvement Act of 1990, which if passed would require that depository libraries apply through the Superintendent of Documents for any government information product, and that such application include the specific cost sharing arrangements proposed among users, the depository libraries, the issuing agency and federal appropriations (Government, 1990).

Joint govermment-industry initiatives may be inevitable, not only because of federal funding constraints, but also because private industry holds advanced search and indexing software necessary for the management of comprehensive, interrelated data stores. Possession of such tools by firms such as Dialog and Nexus place them in an excellent position to bid contracts for on-line or CD-ROM access to federal information (Bortnick \& Relyea, 1990). Joint initiatives are prompted in part by the concern of private industry regarding "unfair" competition with the government if federal information is placed on-line at subsidized rates.

The declining federal budget also may prompt partnerships with private industry in the future. Federal outlays will be a declining proportion of GNP for the rest of the century, with the growth rate of the budget steadily declining (New American, 1986). In recent years, nearly 30 percent of federal spending has gone to pay old-age benefits to the 1] percent of the population currently over 65. Far more will be receiving benefits in the future, as the overall U.S. population ages. In 1986, interest on the national debt (the fastest growing portion of the budget) accounted for 18 percent of all federal spending (Longman, 1988). These and other pressures on the federal treasury may force future information dissemination to be self-sufficient, by means of the involvement of commercial partners.

Access

Skill Requirements

What will be the minimum skill levels required of users and depository librarians in accessing electronically disseminated information?

Projections of median education and skill levels in the future point to a wide divergence in patrons' basic understanding of new technology and the information that it will provide. A dichotomy is developing between a small, undereducated and underskilled younger generation and a larger, educated and job- experienced retirement cohort (Longman, 1988).

Longman also reported that today's younger generation is not only comparatively small (due to low birth rates in the last two decades), but also that an alarming proportion of youth lack the basic skills that employers require. Only 30 percent of today's 17 -year-olds are classified as "adept" readers (i.e., competent enough to go on to college or to cope with business environments). In the early I980s, a 12-nation study found that U.S. average comprehensive scores on seven school subjects always were in the lower third. 
Since 1973, the poverty rate among Americans under 18 has increased more than 50 percent. Each year, hundreds of thousands of young people reach working age without the basic knowledge they need to learn even the simple skills necessary for success in an entry-level job. The implications for their use of depository libraries and access to census data are serious: either data access must be simplified to the extent that the unskilled can retrieve needed information or depository librarians will experience a significantly increased workload acting as intermediaries for such patrons. Otherwise, the unskilled will become disenfranchised (see below).

Nearly all economists agree that the industrialized nations are moving toward information-driven, rather than energy-driven, economies in the next century. The intellectual skills of the labor force in such systems will become increasingly important to maintaining a comparative advantage in international trade. Skills deficiencies among younger patrons may create a frustrated, information underprivileged class with comparatively little real political power.

Fortunately, placement of CD-ROM devices in schools and the development of improved interfaces may make possible gradations of technological user-friendliness in the next 10-20 years, if either funding or equipment and software donations to schools can be arranged. Literacy either in the traditional sense or in a technological sense will decrease in importance. For example, the Library of Congress reading room reconstruction currently under way will include installation of touch screen terminals. It is hoped that such devices will help non-technically sophisticated patrons access the collections (Bortrick \& Ralyea, 1990).

There is some question, however, whether library staff will be skilled enough with the new technology. Part of the startup costs associated with CD-ROM or even online access as an integral part of the Depository Library Program may be the training of staff so they can assist others in using the systems.

\section{Disenfranchisement}

To what degree might user fees and other costs of accessing electronically disseminated information disenfranchise individuals?

Since the founding of the depository library system, it has been presumed that participatory democracy dictated widespread dissemination of public information. However, the increasing cost of the distribution effort is causing this premise to be reexamined. Some information specialists question the societal costs and benefits of universal information suffrage (Bortnick \& Relyea,
1990). They ask

1. Is widespread dissemination of public information essential to the preservation of an acceptable level of shared values among citizens?

2. Would access charges imperil that acceptable level of shared values and create an information underclass?

Future technology may provide the flexibility to manage funding problems, making possible the continued widespread availability of information.

Expensive, on-line access is not essential. More economical CD-ROM media will be cheaper, and enhanced video systems costing no more than a TV does today will provide cheap, multimedia access (Bortnick \& Relyea, 1990). To the extent that direct broadcast satellite reception and public access cable channels are available, those technologies may serve to democratize information dissemination. (Direct broadcast is in use over India today. As minimum antenna diameter shrinks to less than a meter, home satellite reception may become much more widespread than it is today. Also, within the decade there may be enough cable capacity that almost any group that wants its own channel can have it for special broadcasts (New American, 1986).)

However, if market forces are allowed free reign, history suggests that large businesses and institutions will have disproportionate access to the new technology (and to the information it provides), because they are most able to afford capital and staffing costs and will have the most influence in information systems development. If funding continues to be a problem, younger individuals may be disadvantaged in comparison to older users, companies and universities.

\section{User Demand}

What impact will changes in work force composition and employment arrangements have upon the types of census information sought by users?

\section{The Aging Population}

The number of Americans over age 75 will grow almost 35 percent by the year 2000 . The U.S. population 65 or over in 2035 will be 22 percent, vs. 12 percent in 1985 (Haub \& von Cube, 1987). Currently, one of three Americans is between 27 and 42 (the Baby Boom generation). The oldest boomers are just 19 years away from reaching the current average age of retirement (Longman, 1988). One consequence of changes in age distribution will be an increase in two-generation geriatric families during the $1990 \mathrm{~s}$ - adult children in their 
60 s and 70 s caring for parents in their 90s (Outlook, 1989).

The population of retirees will be characterized by a higher average level of education, a friendliness toward business and free enterprise, entrepreneurism, a skepticism toward big government, an inclination to regionalism, and a preference for decentralized regulation (New American, 1986).

Between 1970 and 1980, life expectancy at 65 increased more than nine percent (life expectancy at birth increased only three percent, thus the fastest growing segment of the population is the age group over 80 ). Both the absolute number and the proportion of the population under 25 are declining. By 1995 , people 16 to 24 will be only 16 percent of the population (they were 25 percent in 1980) (Longman, 1988). Serious attempts to slow the human aging processes and prolong life expectancy may begin within the next decade (Outlook, 1989). By the Year 2000 , life expectancy will be 72.9 years for males and 80.5 years for females (New American, 1986).

Also, the physical design and environment of America (information services included) will start to change in the 1990s to accommodate a middle-aged and older population. (For example, traffic lights will change more slowly, allowing more time for less-agile people to get across intersections).

The graying of America may have a significant impact upon the types of information sought by individuals (and institutions operating on their behalf). Seniors are likely to have a special interest in census data because of its link to medical and social security benefits, its bearing upon investment and savings decisions, and its potential as ammununition in lobbying Congress. They will have more time to focus upon and use available data, and will constitute a trained, educated clientele able to make drastically increased demands upon the system.

\section{Changes In The Work Force}

By the year 2000, 95 percent of all jobs will be in service industries that require workers who are familiar with computers and other information processing technologies.

The U.S. may move toward a dual economy, where professionals, scientists, engineers, technicians and other skilled employees are on one end of the spectrum and a large number of blue-collar workers, clerks, and service workers are on the other (Lamm, 1985).

Telecommuting and other flexible-place, flexible-time work schedules will become increasingly common as employers acknowledge modem realities such as single parent households and the stress of urban commuting
(Outlook, 1989). Changes in information need, therefore in the use of depository library material, are certain to follow such changes in lifestyle. Hobbies, travel, and intellectual pursuits may become higher priority for some, while others seek inforamtion in self-help, quality of life areas.

Retirement may become a thing of the past, as seniors remain in jobs at all levels in the workplace. Many people will retum to work after a sabbatical, act as consultants or become "senior apprentices" to learn new skills for a second or even third career (Outlook, 1989).

\section{Multilingual Services}

Work force and patron demographics also will drive the development of multilingual information services in the next century's depository program. The population growth of 12 percent anticipated for the next 15 years will result almost encirely from high level immigration and from the higher-than-replacement birthrate of new immigrants (mostly Hispanic). In the mid-1990s, Mexico's proportion of young job-seekers is due to about double, while the kinds of entry-level jobs they seek at home will shrink drastically. The result will be enormous pressures at the border which will not be entirely unwelcome, as U.S. employers struggle to deal with a shortage of American-born youngsters in the labor force. The user community of the future will include a steadily rising percentage of racial minorities, many using English as a second language. By the Year 2000, 11 percent of the population will be Hispanic and four percent Asian; by 2020, Hispanics will be 15 percent (New American, 1986).

Patrons whose first language is not English are likely to need information in their native language, regarding culturally specific subjects at variance with those sought currently by typical depository library patrons. Immigration, employment and family data may be more important to this group than to the population at large.

The growth in non-English patrons also may add impetus to the development of non-culturally specific interfaces. Even with new storage technology, simultaneous storage of text in Asian and Hispanic languages as well as English could be prohibitively expensive, as demonstrated by the Canadian experience with French and English. However, automatic translation systems being developed as part of the next generation of computers may help solve the multilingual problem. By the year 2000 , computers with automatic language translation and voice-synthesis capabilities may enable people to speak in one language that listeners will hear translated into another language (Outlook, 1989).

Key Issues Requiring Public Debate A number of key issues settled out of the literature 
review and interviews conducted for this study. These are issues that either policymakers, the Bureau of the Census or the depository libraries need to address before developing technology forces less than optimal solutions.

Policymakers

Should future information dissemination be oriented toward individual users or toward businesses and institutions?

Political and fiscal reality dictates that dissemination decisions weigh business and institutional concerns over those of individuals. These may include predominant formats, time of availability for on-line services, content of information disseminated, and fee structures. However, an effort should be made to ensure that institutions served by depository dissemination are reasonably responsive to individuals' requests, even if fees are charged for services rendered.

Should joint ventures with private industry be pursued as a means of funding future dissemination in the face of a shrinking federal budget?

Fiscal reality may force government into partnerships with public database agencies, and to take advantage of advanced indexing and retrieval software and to defray data generation costs. However, in order to protect the public's right to access government information, some regulation of user fees charged by industry partners may be necessary.

What policies should be adopted regarding intellectual property rights in data analysis, access software development and copyright protection?

Partnerships with industry will require special copyright provisions to protect the rights of government's partners, despite the fact that the products withheld would be generated in part with public funds. Contract provisions should state explicitly that key material is not "work for hire", allowing contractors rather than the government to retain copyright. Patents should be filed jointly by contractors and the government. These protections will need to extend specifically to indexing and retrieval software and network protocols developed in support of national on-line access systems. Government will no longer be able to claim its right to contractor source code and algorithms as a condition of working with private industry.

How and where should advanced indexing and retrieval software be procured for access to machine-readable data?
If government enters into a partnership with private industry for database management, the vital access software will come from existing high quality products held by commercial firms. Othenwise, a major contracting effort will need to be staged to have suitable software developed for use with electronically disseminated federal information. Since technology will be evolving rapidly, the decision to develop software under government auspices would be a long term commitment of funds and manpower.

What role should be played in coordination of federal information dissemination policy to eliminate fragmentation of jurisdiction over media, content and formats?

It is clear that a single, centralized agency is needed to coordinate electronic dissemination of federal information. A quasi-government entity including representatives from major actors such as the GPO, Congressional agencies and depository libraries could be organized under an Institute for Information Policy \& Research (as described in HR744, 1985). The tendency to date has been for each agency to select its own standards and media without regard for activities elsewhere in government. Further, conflicting funding and advocacy situations within congress and the executive branch have frustrated standards development. The Bureau of the Census should mount a concerted effort to help resolve the jurisdictional confusion that currently exists.

\section{Bureau of the Census}

How should demands for multilingual presentation beaddressed?

There are two politically acceptable options. Either data should be disseminated through the Depository Library Program in English and Spanish, or it should be formatted in a markup language compatible with automatic translation from English to a handful of user native languages. It may be necessary to disseminate in two languages until the technology is commonly available to perform the automatic translation.

To what extent is the Census Bureau liable for ensuring the integrity of data disseminated in machine-readable formats?

The Census Bureau's liability for the integrity of electronically disseminated data is a question for serious legal consideration in a relatively new area of the law. A comprehensive study of legal issues related to data integrity and other aspects of the new technology needs to be conducted. These include tort liability for damages due to the use of inaccurate or corrupted data and product 
liability in case dissemination includes destructive computer viruses or defective media which physically damage depository library equipment.

Would the Census Bureau be accountable for invasion of privacy or threats to defense or industry confidentiality that might result from the ability to manipulate data in machine-readable format (the "mosaic" issue)?

This issue may either be a moot point, overtaken by extensive network integration worldwide, or a major impediment to widespread dissemination. The Census Bureau needs to examine not only its legal liability regarding privacy issues, but also its political defenses against corporate and DoD initiatives that are certain to be fielded <end indent both>as the technology makes machine manipulation of public data possible.

To what extent should the Census Bureau be involved in establishment of network protocol and human interface standards both within government and within industry?

The history of technological innovation has proven that those who are not actively involved in standards setting activities incur both real financial costs and intangible political losses when standards drafted by others are implemented. Despite considerable expenditures of manpower and other resources, the Bureau of the Census must attempt to guide the establishment of protocol and interface standards.

How should responsibility and costs be divided for creation and maintenance of on-line access networks?

When on-line access becomes feasible, the Bureau of the Census should implement the supercomputer centers model to create and support the system. Businesses and institutions should provide hardware and staff support, while government maintains network interconnects and polices protocol standards.

Should the Census Bureau abandon the depository library program in favor of altemative means of data dissemination, or be a driving force in effecting a restructuring of the program in keeping with new information needs and dissemination technology?

The existing depository library program may need substantial revision (e.g., removal of select libraries, assessment of user fees, and collection specialization in terms of media and content). If required, this might be accomplished via a cooperative arrangement with federal agencies and other depository libraries. However, given that near future electronic dissemination is likely to be via $C D-R O M$ rather than on-line database access, the distribution channels and procedures of the current program may be useful into the next century. If direct access by patrons using integrated networks or through data centers becomes predominant, Census Bureau participation in the depository library program may be abandoned.

\section{Depository Libraries}

What types of training should be provided for depository library staff to better enable them to deal with the challenges of new technology?

Member libraries need to train staff in two key aspects of new technology application: (1) how to operate and maintain local hardware and software themselves and (2) how to best instruct and guide patrons in use of the technology. Neither task will be easy, since there may be significant differences among librarians in their degree of technological sophistication (and motivation). Preparation of a training cadre for the Depository Library Program should be undertaken immediately, funded jointly by the Bureau of the Census, Congress and the GPO. These master instructors in turn should brief library training of ficers who could provide ongoing familiarization at each Program site.

To what extent should collection acquisition, operating and other funds be diverted to the purchase of hardware and software to support the use of electronically disseminated information?

It may be difficult to convince librarians to spend limited funds on equipment to support user access rather than on collection acquisition. However, in the long term funds spent on electronic equipment will result in more extensive and productive access to existing collections. Because of the density of electronically disseminated data, money invested in CD-ROM and associated printers and services will quickly expand a library's actual collection even as funds devoted to traditional acquisition decline. Expenditures for hardware, software and services related to electronic media should be a significant line item in each facility's budget.

\section{Further Research}

Should the Census Bureau decide upon the medium and content of information disseminated based upon extent and type of use research?

Given the resistance of the library community and the seeming lack of space concerns for projected media, it would seem unwise to attempt limiting the kinds of 
information disseminated through the Depository Library Program. However, it would be prudent to undertake a systematic and ongoing study of usage patterns in case budget or technological constraints make filtering necessary in the future. Patron preferences for specific media in accessing certain types of information should be evaluated.

\section{Conclusion}

This study was fielded under the presumption that government will be required to continue providing public access to federal information as part of its commitment to maintaining the informed citizenry that is central to participatory democracy.

The nature of that access, however, is entwined in a host of social, economic and technology issues that must be addressed promptly if the pace of change is not to overwhelm policymakers as well as information intermediaries and users.

Information will be central to the knowledge economy of postindustrial America. However, the population will be split between a relatively affluent, educated retirement community and a smaller unskilled, undereducated younger group less able to deal with sophisticated information access.

The generation and dissemination of knowledge will be dependent upon the degree of protection for intellectual property in an environment that features easy unauthorized copying of proprietary materials. The technology predominant at depository libraries will be CD-ROM, with on-line database services a distant second, used mainly for current updates of timely information.

Before emerging technology can approach its potential, problems of efficient indexing and retrieval software, hardware compatibility and protocol standards must be resolved. Perhaps key in this effort will be a relaxation of anti-trust regulation to facilitate cooperative research, development and manufacture by major players in the telecommuncations and computing industries.

Ultimately, the twin issues of funding and regulation underlie all concerns regarding future information technology. Given the declining resources of federal government, privatization and user fees seem inevitable. Privatization brings with it the prospect of reduced access to public information, and user fees the near certainty of disenfranchisement for a new underclass: the information disadvantaged.

These problems are not intractable. However, significant changes in the way we fund, generate, control and disseminate public information will be forced by techno- logical change. If indeed those who do not learn from the past are condemned to repeat it, those who do not anticipate the future may be destined to live it amidst laments of what might have been.

\section{References}

Bell, D. (1978). The postindustrial economy. in J. Fowles, Handbook of Futures Research. Westport, Conn.: Greenwood Press, 507-514.

Bezold, C. \& Olson, R. (1986). The Information Millenium: Alternative Futures. Washington: Information Industry Assn.

Bortnick, J. \& Relyea, H. (1990, March 30). Interview at the Madison Building, Library of Congress, Washington, D.C.

Caddy, D. (1987). Exploring America's Future. College Station, Tex.: Texas A\&M Univ. Press.

Cetron, M. (1988). Into the 21 st century. The Futurist, $22: 4,29-40$.

Clarke, A. (1978). Communications in the future. In J. Fowles, Handbook of Futures Research. Westport, Conn.: Greenwood Press, 637-652.

Comish, E. (1985). The library of the future. The Futurist, 19:6, 2, 39.

Diebold, J. (1985). New challenges for the information age. The Futurist, 19:3, 68 .

Eldredge, H. (1978). Urban Futures. In J. Fowles, Handbook of Futures Research. Westport, Conn.: Greenwood Press, 617-636.

Federal information center program (1990). [A background paper.] (Available from the GSA Information Resources Management Service, Washington, DC 20405).

Freese, R. (1988). Optical disks become erasable. IEEE Spectrum, 26:2, 41-45.

Government printing office improvement act of 1990 . [HR 3849]. (Available from the Superintendent of Documents, Washington, DC).

Harm is averted by quick response to computer virus (1990). Administrative Notes, II (April 13), 1. Newsletter of the Federal Depository Library Program.

Haub, C. \& von Cube, A. (1987). The United States 
Population Data Sheet (6th ed.). Washington, D.C.: Population Reference Bureau. In Marien, M. (Ed.), Future Survey Annual (Item Nr. 8369). Washington, D.C.: World Future Society.

Hemon, P. \& McClure, C. (1987). Federal lnformation Policies in the 1980's: Conflicts and Issues. Norwood, N.J.: Ablex.

Lamm, R. (1985). Megatraumas: America At the Year 2000. Boston: Houghton Mifflin.

Longman, P. (1988). The challenge of an aging society. The Futurist, 23:5, 33-37.

Marshall, C. \& Rossman, G. (1989). Designing Qualitative Research.Newbury Park, Calif.: Sage.

McGee, Milton (1990, March 30). Interview at the Adams Building, Library of Congress, Washington, D.C.

The New American Boom. (1986). Kiplinger Washington Letter. Washington, D.C.: The Kiplinger Washington Editors, Inc. 1988 Ten-Year Forecast. (1988). Menlo Park, Calif.: Institute For the Future. Outlook '90 and beyond. (1989). The Futurist, 23:6, 53-60.

Powell, Elizabeth (1990, February 16). Interview at the Hart Senate Office Building, Washington, D.C.

Tenner, E. The Revenge of Paper. The New York Times, March 5, 1988, 27.

Weiner, E. \& Brown, A. (1989) Human factors: The gap between humans and machines. The Futurist, 23:3, 9-11.

Weinstein, S. \& Shumate, P. (1989). Beyond the telephone: new ways to communicate. The Futurist, 23:6, 812.

\section{Additional Sources}

The following sources were identified in the literature search for this study, but are not referenced in the final report.

Comish, E. (Ed.) (1982). Communications Tomorrow. Bethesda, Md.: World Future Society.

Didsbury, H. (Ed.) (1982). Communications and the Future. Bethesda, Md.: World Future Society.

Dowlin, K. (1984). The Electronic Library. New York: Neal-Schuman.

Ferrarotti, F. (1986). Five Scenarios for the Year 2000. New York: Greenwood Press.
Gorman, M. (Ed.) (1984). Crossroads. (Proceedings of the First National Conference of the Library and Information Technology Assn., Sept. 17-21, 1983, Baltimore, Md.). Chicago: American Library Assn.

Naisbitt, J. (1982). Megatrends. New York: Warner Books.

Pasqualini, B. (Ed.) (1987). Dollars and Sense: 1mplications of the New Online Technology for Managing the Library. Chicago: American Library Assn.

${ }^{1}$ Presented at the IASSIST 90 Conference held in Poughkeepsie, N.Y. May 30 - June 2, 1990.

The author may be contacted at 4-290 Center for Science and Technology, Syracuse University, Syracuse, NY $13244-4100$, or at

D01DAYXX@SUVM.ACS.SYR.EDU.

${ }^{2}$ Hemon, P., McClure, C., \& G. Purcell (1985). GPO's Depository Library Program. Norwood, N.J.: Ablex.

${ }^{3}$ Some information intermediaries believe it is important that federal information be made available via the latest technologies (J. Stratford, personal communication, February 21,1990 ). However, problems with inconsistent file formatting and a lack of satisfactory retrieval software have made tests of experimental census distribution on CD-ROM less than a complete success (K. Chiang, personal communication, April 12, 1990). Problems of information policy making within a web of overlapping agency jurisdictions also have frustrated modemization efforts.

${ }^{4}$ Hudson, R. (1990, April 5). IBM researchers "write" with atoms on a metal surface. The Wall Street Journal, p. B4.

${ }^{4}$ Reauthorization of the Paperwork Reduction Act (1989). Hearings before the Subcommittee on Govemment Information and Regulation of the Committee on Govemmental Affairs United States Senate (Senate hearing 101-166; Document 19-630). Washington, D.C.: U.S. Govemment Printing Office.

${ }^{6} \mathrm{OMB}$ Circular A-76 mandated that agencies determine whether it would be more beneficial to continue to perform functions with government employees or to contract them out to the private sector (Govemment, 1990). 